\title{
Failure of anti Interleukin-1 $\beta$ monoclonal antibody in the treatment of recurrent pericarditis in two children
}

\author{
Sara Signa ${ }^{1,2}$, Matteo D’Alessandro ${ }^{1,2}$, Rita Consolini ${ }^{3}$, Angela Miniaci ${ }^{4}$, Marta Bustaffa ${ }^{1,2}$, Chiara Longo ${ }^{1,2}$, \\ Maria A. Tosca ${ }^{5}$, Martina Bizzi ${ }^{3}$, Roberta Caorsi ${ }^{1}$, Leonardo Oliveira Mendonça' ${ }^{1}$ Andrea Pession ${ }^{4}$, \\ Angelo Ravelli2, ${ }^{2,6}$ and Marco Gattorno ${ }^{1 *}$
}

\begin{abstract}
Background: Recurrent pericarditis (RP) is a complication (15-30\%) of acute pericarditis with an unknown etiology. Treatment regimen consists of a combination of non-steroidal anti-inflammatory drugs (NSAIDs) and colchicine, with the addition of corticosteroids in resistant or intolerant cases. In the last decade anakinra was shown as an effective treatment in patients with colchicine resistant and steroid-dependent RP, initially in anecdotal reports in children and more recently in a randomized trial. Canakinumab is a monoclonal antibody selectively blocking IL-1 $\beta$ and its use is only anecdotally reported to treat pericarditis. We report two pediatric patients with refractory recurrent pericarditis, who presented an optimal response to anakinra treatment but prompt relapse after switch to canakinumab.

Case presentation: The first patient is a girl with Recurrent Pericarditis started in April 2015, after heart surgery. NSAIDs and oral steroids were started, with prompt relapse after steroid suspension. The child showed a steroiddependent RP; anakinra was therefore started with excellent response, but discontinued after 2 weeks for local reactions. In July 2016 therapy with canakinumab was started. She experienced four relapses during canakinumab therapy despite dosage increase and steroid treatment. In January 2018 a procedure of desensitization from anakinra was performed, successfully. Anakinra as monotherapy is currently ongoing, without any sign of flare. The second patient is a girl with an idiopathic RP, who showed an initial benefit from NSAIDs and colchicine. However, 10 days after the first episode a relapse occurred and therapy with anakinra was established. Two months later, while being in complete remission, anakinra was replaced with canakinumab due to patient's poor compliance to daily injections. She experienced a relapse requiring steroids 10 days after the first canakinumab injection. Anakinra was subsequently re-started with complete remission, persisting after 24 months follow-up.

Conclusions: We describe two cases of failure of the treatment with anti-IL-1 $\beta$ monoclonal antibodies in steroiddependent idiopathic RP. This anecdotal and preliminary observation suggests a different efficacy of the two IL-1 blockers in the management of RP and support a possible pivotal role of IL-1a in the pathogenesis of this condition.
\end{abstract}

Keywords: Recurrent pericarditis, Interleukin-1 $\beta$, Interleukin-1 a, Anakinra, Canakinumab

\footnotetext{
* Correspondence: marcogattorno@gaslini.org

1 UOSD Centro Malattie Autoinfiammatorie ed Immunodeficienze, IRCCS Istituto Giannina Gaslini, Via Gerolamo Gaslini 5, 16147 Genoa, Italy Full list of author information is available at the end of the article
} 


\section{Background}

Recurrent pericarditis (RP) is a complication (15-30\%) of acute pericarditis with an unknown etiology [1]. Treatment regimen consists of a combination of nonsteroidal anti-inflammatory drugs with colchicine with the addition of corticosteroids in resistant or intolerant cases [2]. Anakinra is a therapeutic option as steroidsparing agent, as recently demonstrated by the first anecdotal reports in children and adults [2-4] and corroborated by the recent AIRTRIP trial [5] and IRAP study [6]. Anakinra neutralizes the biologic activity of interleukin- $1 \alpha$ (IL-1 $\alpha)$ and interleukin-1 $\beta$ (IL-1 $\beta$ ) by inhibiting their binding to IL-1 type I receptor. Another IL-1 blocker is canakinumab, a monoclonal antibody that selectively blocks IL-1 $\beta$ in circulation. Canakinumab treatment in pericarditis has been reported only anecdotally $[7,8]$ and its effectiveness in treating this clinical manifestation need to be further inquired and validated.

We report our experience concerning Canakinumab in two pediatric patients suffering from refractory recurrent pericarditis, who presented an optimal response to anakinra treatment but prompt relapse after the canakinumab therapy start. One patient needed desensitization procedure to anakinra to reintroduce the treatment and achieve clinical remission.

\section{Case presentation}

Patient 1 is a 10-years old girl, admitted to our hospital in 2016 because of RP started in June 2015, 2 months after a surgical correction for atrial septal defect. Non steroidal anti-inflammatory drugs (NSAIDs), colchicine and oral steroids were started and then gradually tapered, with a disease flare after the steroid suspension, requiring pericardiocentesis. The child showed a steroiddependent RP, with several relapses at steroid tapering. In March 2016, after five relapses, anakinra $(2 \mathrm{mg} / \mathrm{kg} /$ day) was started, with a fast and complete clinical response. However, it was discontinued after 2 weeks for the appearance of a diffuse itchy urticarial rash and a delayed local response with swelling and erythema at the injection site, unresponsive to antihistamines. Due to the persistence of pericarditis relapses and steroid dependency despite colchicine treatment, in July 2016 canakinumab was started $(4 \mathrm{mg} / \mathrm{kg}$ every 4 weeks) with NSAIDs and steroids, that were subsequently gradually tapered. During the following 6 months, the patient presented four relapses at any attempt to reduce the steroids below $0.25 \mathrm{mg} / \mathrm{kg} /$ die. The modification of the schedule of canakinumab administration to $4 \mathrm{mg} / \mathrm{kg}$ every 3 weeks and the reintroduction of Colchicine were not beneficial. Therefore, in December 2017 canakinumab was withdrawn. Due to the severe steroid toxicity, we decided to attempt the reintroduction of anakinra after desensitization process, as previously reported in other patients with IL-1-mediated conditions [9] and summarized by Yilmaz [10]. The desensitization started in January 2018 with five to three consecutive injections per day of gradually increasing anakinra doses and dilutions from days 1 to 9 (Table 1). Each injection was spaced by 15 min intervals, raising the dose at each step. On Day 2,

Table 1 Desensitization to anakinra schedule. Desensitization pre medication: cetirizine $10 \mathrm{mg}$ twice a day and oral metilprednisolone $4 \mathrm{mg}$ twice a day

\begin{tabular}{|c|c|c|c|}
\hline & TIME INTERVAL (minutes) & DOSE (mg) & DILUTION $(\mathrm{mg} / \mathrm{mL})$ \\
\hline \multirow[t]{5}{*}{ Day 1} & 0 & 0,1 & 1 \\
\hline & 15 & 0,3 & 1 \\
\hline & 30 & 0,6 & 1 \\
\hline & 45 & 1 & 5 \\
\hline & 60 & 2,5 & 5 \\
\hline \multirow[t]{5}{*}{ Day 2} & 0 & 2,5 & 5 \\
\hline & 30 & 3,75 & 5 \\
\hline & 60 & 5 & 5 \\
\hline & 90 & 6,25 & 10 \\
\hline & 120 & 7,5 & 10 \\
\hline \multirow[t]{4}{*}{ Day 3} & 0 & 7,5 & 10 \\
\hline & 30 & 8,75 & 10 \\
\hline & 60 & 10 & 20 \\
\hline & 90 & 12,5 & 20 \\
\hline \multirow[t]{3}{*}{ Day 4} & 0 & 8,75 & 10 \\
\hline & 30 & 10 & 10 \\
\hline & 60 & 12,5 & 20 \\
\hline \multirow[t]{3}{*}{ Day 5} & 0 & 12,5 & 20 \\
\hline & 30 & 15 & 20 \\
\hline & 60 & 17,5 & 20 \\
\hline \multirow[t]{3}{*}{ Day 6} & 0 & 17,5 & 40 \\
\hline & 30 & 20 & 40 \\
\hline & 60 & 22,5 & 40 \\
\hline
\end{tabular}

Day $7-0 \quad 22,5 \quad 40$

\begin{tabular}{llll} 
& 30 & 25 & 40 \\
Day 8 & 60 & 30 & 40 \\
& 0 & 30 & 40 \\
& 30 & 20 & 40 \\
Day 9 & 60 & 30 & 40 \\
& 30 & 30 & 60 \\
Day 10 & 0 & 20 & 60 \\
& 30 & 30 & 60 \\
& 30 & 30 & 149 \\
Day 11 & 0 & 20 & 149 \\
& 30 & 30 & 149 \\
\hline
\end{tabular}


due to the appearance of skin reactions at injection site, the interval between the injections was increased to $30 \mathrm{~min}$ with increased dilution, restarting the desensitization protocol. The full target dosage (80 $\mathrm{mg} /$ day; $2 \mathrm{mg} / \mathrm{kg} /$ day) at standard dilution (divided in 4 different administrations) was reached on Day 8. Since Day 11 anakinra was administrated twice a day. Antihistaminic and steroids were administrated during all the desensitization process and extremely slowly tapered in the subsequent 6 months due to the persistence and recurrence of local erythema and edema at the injection site (Fig. 1). Anakinra was finally administrated once a day since June 2018. Antihistamines and steroids were definitively stopped, without recurrence of either skin reactions or disease flares. In June 2018, low-dose colchicine was progressively tapered and finally discontinued. After 24 months follow-up, the patient is still on daily anakinra as monotherapy. Neither flares of pericarditis nor injections skin reactions were observed anymore (Fig. 2).

Patient 2 is an 11-years-old girl with idiopathic RP, diagnosed in April 2017, requiring a pericardiocentesis at disease onset. She initially benefit from NSAIDs and colchicine. However, 10 days after the first episode a relapse occurred; anakinra was therefore started with a

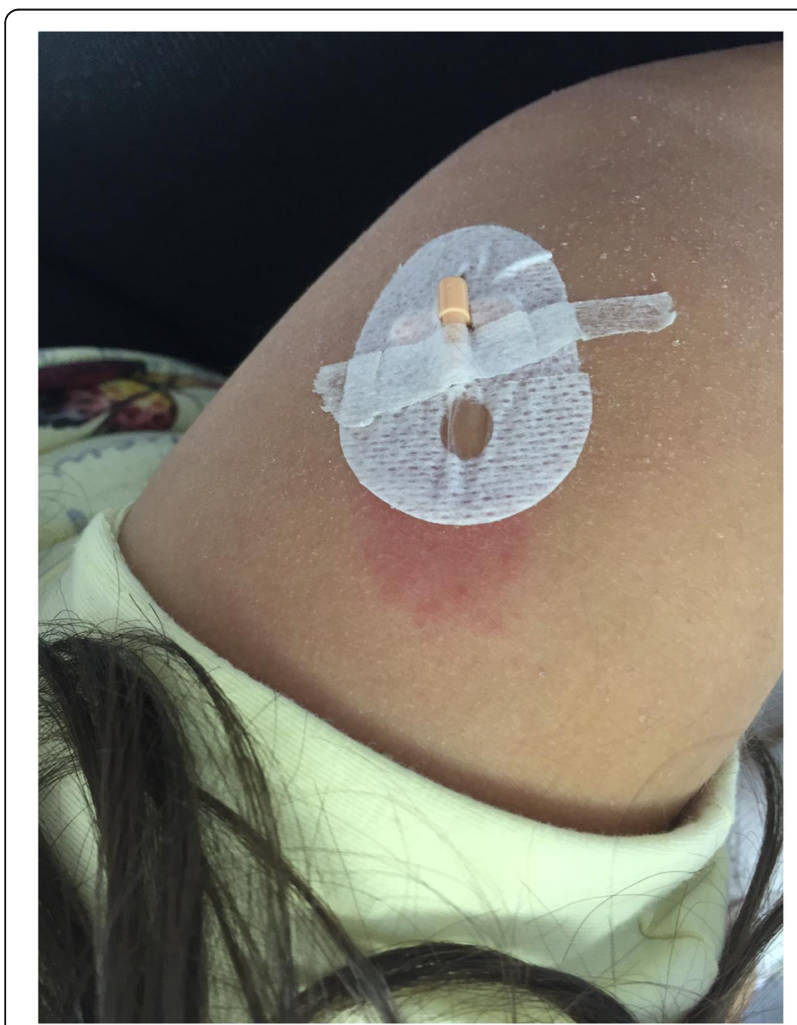

Fig. 1 Local erythema and edema at anakinra injection site in patient 1 dramatic and complete response. Two months later, while the patient was in in complete remission, anakinra was replaced with canakinumab $(2.5 \mathrm{mg} / \mathrm{kg} / \mathrm{dose})$ due to poor compliance to daily injections. Ten days after the first canakinumab injection she experienced a severe relapse requiring oral steroids. Anakinra $(2 \mathrm{mg} / \mathrm{kg} /$ day $)$ was re-started allowing fast steroid tapering. She showed complete remission in anakinra as monotherapy, persisting after 26 months follow-up.

\section{Discussion and conclusions}

We describe two cases of substantial treatment failure with anti-IL-1 $\beta$ monoclonal antibodies treatment in RP, one idiopathic and one post-pericardiotomy. In both, a good response to recombinant IL-1 receptor antagonist as monotherapy was achieved. Notably, while canakinumab is selectively targeting IL-1 $\beta \quad$ anakinra prevents the biological activity of both IL- $1 \alpha$ and IL- $\beta$. The active IL-1 $\beta$ is secreted by monocytes and macrophages the activation of the Inflammasomes. Conversely, IL- $1 \alpha$ is constitutively expressed in several types of cells at steady state, especially in epithelial cells, activated by cellular stress and massively secreted after cell necrosis [11].

The desensitization from anakinra in patient 1 was rather long and laborious. The timing and type of reaction suggest a mixed IgE and non IgE mediated mechanisms, an justify the longer period needed to achieve a complete result than previously described in the literature [10]. Nonetheless, the process allowed the complete control of disease flares with a relevant impact on patient's quality of life.

An anecdotal observation [7] of good answer to canakinumab in two Adult-onset Still's Disease patients with pericarditis was reported, whereas a third patient with seronegative RA relapsed, requiring steroid therapy. In pediatric patients a case of a child with idiopathic RP with anaphylactic reaction to anakinra was recently described [8]. In this case very high doses $(5 \mathrm{mg} / \mathrm{kg}$ monthly) of canakinumab were able to maintain the clinical remission in association with colchicine. While all data so far available in the literature show the possibility to obtain complete response with anakinra in RP, at least when used as the scheduled daily regimen $[1,5$, $12]$, the present report suggest that anti-IL-1 $\beta$ monoclonal antibody may have a less clear impact in the treatment of this condition. This might support the relevance of IL-1 $\alpha$ in the induction and maintenance of the inflammatory response at the tissue level in idiopathic pericarditis [11].

In conclusion, we describe two cases of substantial failure of the treatment with anti-IL-1 $\beta$ monoclonal antibodies treatment in steroid- dependent idiopathic RP. In both case a good response to the treatment with 


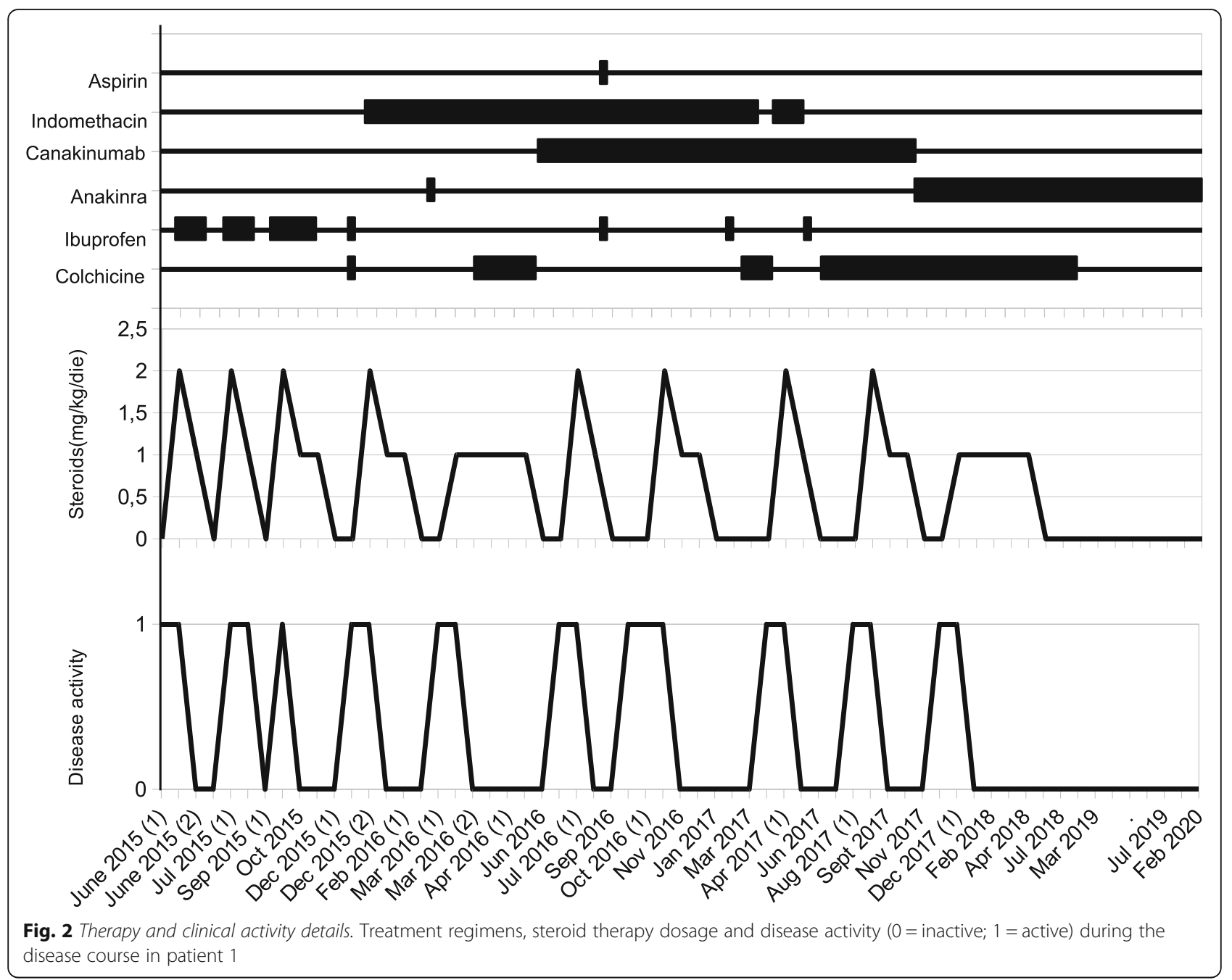

recombinant IL-1 receptor antagonist was achieved. These anecdotal and preliminary observations suggest a different efficacy of the two IL-1 blockers in the management of recurrent pericarditis and may stimulate further inquiries on the role of IL-1 (particularly IL-1 $\alpha$ ) in the induction and maintenance of the inflammatory response at the tissue level in idiopathic pericarditis.

\section{Abbreviations}

IL-1: Interleukin-1; IL-1a: Interleukin-1 a; IL-1ß: Interleukin-1 B;

NSAIDs: Nonsteroidal anti-inflammatory drugs; RP: Recurrent pericarditis

\section{Acknowledgements}

We thank patients and families.

\section{Authors' contributions}

Study concept and design: MG, SS, RC, LOM; acquisition of data: SS, MD, MB, $C L, M B, A M, R C$; drafting of the manuscript: SS, MT, AM, RC, MG; critical revision of the manuscript for important intellectual content: AM, AP, RC, MT, LOM, RC, AR, MG; study supervision: RC and MG. All authors read and approved the final manuscript.

Authors' information

Not applicable.
Funding

No funding was received for this work.

Availability of data and materials Not applicable.

Ethics approval and consent to participate

The treatment was approved by IRCCS G.Gaslini Institutional Review Board. Patients legal guardians signed a written informed consent.

Consent for publication

Written informed consent was obtained from the parents for publication.

\section{Competing interests}

MG: Speakers' fees, consultancies and unrestricted grants from Novartis and Sobi. LOM: speaker's fees from Novartis and is a recipient of longterm fellowship in autoinflammatory diseases from the European Society of Immunodeficiencies at Giannina Gaslini Institute. The other authors declare that they have no relevant conflicts of interest.

\section{Author details}

'UOSD Centro Malattie Autoinfiammatorie ed Immunodeficienze, IRCCS Istituto Giannina Gaslini, Via Gerolamo Gaslini 5, 16147 Genoa, Italy. ${ }^{2}$ DINOGMI, Università di Genova, Genoa, Italy. ${ }^{3}$ Clinica pediatrica, Università di Pisa, Pisa, Italy. ${ }^{4}$ Pediatric Unit, Department of Medical and Surgical Sciences, S. Orsola Hospital, University of Bologna, Bologna, Italy. ${ }^{5}$ UOSD Centro 
Allergologia IRCCS Istituto Giannina Gaslini, Genoa, Italy. ${ }^{6}$ Clinica Pediatrica e Reumatologia, IRCCS Istituto Giannina Gaslini, Genoa, Italy.

Received: 3 March 2020 Accepted: 3 June 2020

Published online: 16 June 2020

\section{References}

1. Imazio M, Gaita F. Acute and recurrent pericarditis. Cardiol Clin. 2017;35(4): 505-13. https://doi.org/10.1016/j.ccl.2017.07.004.

2. Brucato A, Emmi G, Cantarini L, et al. Management of idiopathic recurrent pericarditis in adults and in children: a role for $\mathrm{IL}-1$ receptor antagonism. Intern Emerg Med. 2018;13(4):475-89. https://doi.org/10.1007/s11739-0181842-X.

3. Picco P, Brisca G, Traverso F, Loy A, Gattorno M, Martini A. Successful treatment of idiopathic recurrent pericarditis in children with interleukin-1 $\beta$ receptor antagonist (anakinra): an unrecognized autoinflammatory disease? Arthritis Rheum. 2009;60(1):264-8. https://doi.org/10.1002/art.24174.

4. Galluzzo A, Imazio M. Advances in medical therapy for pericardial diseases. Expert Rev Cardiovasc Ther. 2018;16(9):635-43. https://doi.org/10.1080/ 14779072.2018.1510315.

5. Brucato A, Imazio M, Gattorno M, et al. Effect of Anakinra on recurrent pericarditis among patients with colchicine resistance and corticosteroid dependence. JAMA. 2016;316(18):1906. https://doi.org/10.1001/jama.2016. 15826.

6. Imazio M, Andreis A, De Ferrari GM, et al. Anakinra for corticosteroiddependent and colchicine-resistant pericarditis: the IRAP (international registry of Anakinra for pericarditis) study. Eur J Prev Cardiol. 2019. https:// doi.org/10.1177/2047487319879534

7. Kougkas N, Fanouriakis A, Papalopoulos I, et al. Canakinumab for recurrent rheumatic disease associated-pericarditis: a case series with long-term follow-up. Rheumatology. 2018;57(8):1494-5. https://doi.org/10.1093/ rheumatology/key077.

8. Epçaçan S, Sahin S, Kasapcopur O. Anaphylactic reaction to anakinra in a child with steroid-dependent idiopathic recurrent pericarditis and successful management with canakinumab. Cardiol Young. 2019;29(4):549-51. https:// doi.org/10.1017/S1047951119000672.

9. Mendonca LO, Malle L, Donovan FX, et al. Deficiency of Interleukin-1 receptor antagonist (DIRA): report of the first Indian patient and a novel deletion affecting IL1RN. J Clin Immunol. 2017;37(5):445-51. https://doi.org/ 10.1007/s10875-017-0399-1.

10. Yilmaz TM, Bahçecioğlu SN. Successful rapid subcutaneous desensitization to anakinra in a case with a severe immediate-type hypersensitivity reaction. Eur Ann Allergy Clin Immunol. 2018;50(2):94-6. https://doi.org/10.23822/ EurAnnACl.1764-1489.30.

11. Di Paolo NC, Shayakhmetov DM. Interleukin 1a and the inflammatory process. Nat Immunol. 2016;17(8):906-13. https://doi.org/10.1038/ni.3503.

12. Finetti $M$, Insalaco A, Cantarini $L$, et al. Long-term efficacy of interleukin-1 receptor antagonist (Anakinra) in corticosteroid-dependent and colchicineresistant recurrent pericarditis. J Pediatr. 2014;164(6):1425-1431.e1. https:// doi.org/10.1016/j.jpeds.2014.01.065.

\section{Publisher's Note}

Springer Nature remains neutral with regard to jurisdictional claims in published maps and institutional affiliations.

Ready to submit your research? Choose BMC and benefit from:

- fast, convenient online submission

- thorough peer review by experienced researchers in your field

- rapid publication on acceptance

- support for research data, including large and complex data types

- gold Open Access which fosters wider collaboration and increased citations

- maximum visibility for your research: over $100 \mathrm{M}$ website views per year

At $\mathrm{BMC}$, research is always in progress.

Learn more biomedcentral.com/submissions 